\title{
Langetermijnfollow-up en succespercentage van de urethraplastiek
}

\author{
Pauline C. Wesselman van Helmond ${ }^{1} \cdot$ Ronald I. Nooter $^{1} \cdot$ Anna V. van Lingen ${ }^{1}$
}

Published online: 22 November 2018

(c) The Author(s) 2018

\section{Samenvatting}

De urethraplastiek is de aangewezen behandeling voor langere of recidiverende urethrastricturen. In deze retrospectieve studie werd het succespercentage van 81 urethraplastieken middels excisie en primaire anastomose (EPA) of graftplastiek geanalyseerd, met follow-up van minstens drie maanden. Falen van de plastiek werd gedefinieerd als recidief waarvoor enige vorm van interventie volgde. Met een telefonische enquête en vragenlijst werden de tevredenheid en langetermijncomplicaties geëvalueerd. Het overall succes was 79\%. Voor EPA's en graftplastieken was de ingreep succesvol bij $91,7 \%$ en $72,5 \%$ van de patiënten. Korte bulbaire stricturen kwamen het meest voor. Bij 58,8\% van de recidieven waren voorafgaand meerdere ingrepen verricht voor een urethrastrictuur. Erectiele disfunctie de novo kwam voor bij 22,8\%. Postoperatief bemerkte $14 \%$ verkorting van de penis en $6 \%$ kromstand.

De conclusie is dat het succespercentage van EPA's hoger is dan van graftplastieken. Meerdere voorafgaande instrumentaties voor strictuurbehandeling is mogelijk een risicofactor voor recidief. Erectiele disfunctie lijkt een veel voorkomende complicatie.

Trefwoorden urethrastrictuur $\cdot$ urethraplastiek $\cdot$ succespercentage

\section{Long-term follow-up and success rate of the urethroplasty}

\begin{abstract}
Long and recurrent urethral strictures are treated with urethroplasty. We retrospectively analyzed 81 urethroplasties performed with excision and anastomosis (EPA) or graft urethroplasty, with at least three months follow-up. Failed urethroplasty was defined as recurrence followed by any intervention. Patient's satisfaction and long-term complications were evaluated with a telephone survey and a written questionnaire. The overall success rate was $79 \%$, in EPAs $91.7 \%$ and in graft urethroplasties $72.5 \%$. Most strictures were short and developed in the bulbar urethra. Within the recurrence group $58.8 \%$ had undergone multiple previous treatments for urethral strictures. After surgery $22.8 \%$ had erectile dysfunction. Shortening of the penis was noticed in $14 \%$ and chordee in $6 \%$. In conclusion, the success rate in EPAs is greater than in graft urethroplasties. Multiple treatments for previous urethral strictures could be a risk factor for recurrence. Erectile dysfunction might be an important complication.
\end{abstract}

Keywords urethrastricture $\cdot$ urethroplasty $\cdot$ success rate

\section{Inleiding}

Een urethrastrictuur is een fibrotische vernauwing van de urethra die wordt veroorzaakt door schade aan de urethra. Denk aan iatrogene schade door katheterisatie of transuredrs. Pauline C. Wesselman van Helmond paulinewesselman@gmail.com thrale resectie van de prostaat (TURP). Daarnaast kunnen externe traumata ter hoogte van het perineum, infecties zoals een seksueel overdraagbare aandoening (soa) en lichen sclerosus leiden tot fibrose van de urethra. Desalniettemin is bij het overgrote deel van de urethrastricturen de oorzaak 
idiopathisch [1, 2]. Symptomen bestaan onder andere uit obstructieve mictieklachten, nadruppelen en dysurie. In uiterste gevallen kunnen patiënten een urineretentie ontwikkelen of last krijgen van recidiverende urineweginfecties $[1,2]$. Bij klachten of complicaties als gevolg van een urethrastrictuur bestaat er een behandelindicatie [3].

De aangewezen behandeling voor korte bulbaire stricturen bestaat momenteel uit een primaire urethrotomie of dilatatie [3]. In de literatuur wordt geen verschil in succespercentage gezien, maar de recidiefkans bij beide is hoog en beloopt tot $70 \%$ [1, 2, 4]. Bij langere bulbaire en peniele stricturen of een recidief is een urethraplastiek de aangewezen behandeling [3]. Een urethraplastiek kan worden verricht door middel van excisie van de strictuur en het aanleggen van een anastomose (excisie en primaire anastomose, EPA), ook wel end-to-endplastiek genoemd. Deze methode wordt voor kortere bulbaire stricturen gebruikt [1, 4-6]. Een graftplastiek is gangbaar bij kortere, maar voornamelijk langere bulbaire en peniele stricturen. Bij een graftplastiek wordt de strictuur over de lengte geopend en de diameter verruimd door het inhechten van een graft. De graft kan bestaan uit slijmvlies van de wang, tong, lip of voorhuid [1, 6].

Ook bij de urethraplastiek bestaat de kans op een recidief van de strictuur. In de literatuur worden verschillende succespercentages beschreven, waarbij over het algemeen de EPA een hoger succespercentage heeft dan de graftplastiek $[4,6]$.

Er zijn verschillende opvattingen over de definitie van een succesvolle urethraplastiek. Sommige auteurs zien een plastiek als niet geslaagd wanneer tijdens controle een recidief wordt aangetoond. Anderen zien de noodzaak tot aanvullende vormen van behandeling pas als falen van de plastiek [4]. Vaak wordt hierbij het oordeel van de patiënt niet meegenomen.

Tijdens deze studie is een analyse verricht naar het succespercentage van EPA en graft-urethraplastieken die zijn verricht in het Franciscus Gasthuis (voormalig Sint Franciscus Gasthuis) te Rotterdam in de afgelopen zeven jaar. Er werd gekeken naar factoren die van invloed kunnen zijn op het resultaat van de operatie en de tevredenheid van de patiënt.

\section{Methoden}

In deze retrospectieve studie is een analyse verricht van de data van mannen die tussen 1 januari 2011 en 31 juli 2017 een EPA of graftplastiek ondergingen in het Franciscus Gasthuis te Rotterdam, met een follow-up van ten minste drie maanden. Alle operaties zijn door dezelfde operateur (R.N.) uitgevoerd.
De primaire uitkomstmaat was het slagen van de plastiek. In deze studie is een niet geslaagde plastiek gedefinieerd als een recidief urethrastrictuur waarop enige interventie volgde. Een recidief werd vastgesteld bij controlecystoscopie of bij een cystoscopie die werd verricht op geleide van klachten.

De patiëntgerelateerde kenmerken en per- en postoperatieve factoren zijn verzameld middels statusonderzoek. Patiëntgerelateerde kenmerken betroffen leeftijd, diabetes mellitus, roken, indicatie tot behandeling, oorzaak van de urethrastrictuur, radiotherapie van de prostaat in de voorgeschiedenis en eerdere behandeling voor een urethrastrictuur. Peroperatieve factoren betroffen de duur van de operatie, het type plastiek en bij - onlayplastieken - inhechting van de graft aan de ventrale of dorsale zijde van de urethra. Postoperatieve factoren bestonden uit lekkage die zichtbaar was op het controle-urethrogram drie weken postoperatief en complicaties, zoals infectie, hematoom, erectiele disfunctie en kromstand, of verkorting van de penis. Aanwezigheid van erectiele disfunctie pre- en postoperatief is geanalyseerd aan de hand van de International Index of Erectile Function (IIEF).

De lengte van de urethrastrictuur en een eventueel recidief werden ingeschat door meting op het retrograde urethrogram (X-RUG), terwijl de patiënt in de oblique positionering lag voor optimale beoordeling van de urethra over de gehele lengte, zonder overprojectie [7]. Tevens is op het X-RUG de locatie en het aantal stricturen bepaald. Van meerdere stricturen is sprake als zich tussen de stricturen een lumen bevindt dat in omvang vergelijkbaar is met de rest van de urethra.

De maximale snelheid van de mictiestraal tijdens uroflowmetrie $\left(Q_{\max }\right)$ bij een mictievolume van minimaal $150 \mathrm{ml}$ is pre- en postoperatief vergeleken, om te bepalen of er sprake was van objectieve verbetering van de straal.

De tevredenheid van de patiënt is geëvalueerd met een telefonische enquête met drie vragen: tevredenheid over de huidige mictie, noodzaak tot een nieuwe verrichting, en of er sprake was van verminderde erecties sinds de operatie. Ook was het verzoek om op papier een uitgebreidere vragenlijst in te vullen over de huidige mictie, erecties, eventuele standsverandering van de penis en de algehele tevredenheid. Tevens was er ruimte voor op- of aanmerkingen omtrent de behandeling [8-10].

De data zijn geanalyseerd met SPSS 24. De $\mathrm{Q}_{\max }$ voor en na de plastiek is gemeten met de Willcoxon-test.

\section{Resultaten}

In het Franciscus Gasthuis ondergingen tussen 1 januari 2011 en 31 juli 201791 patiënten een urethraplastiek, van wie 81 met een follow-up van minstens drie maanden. De 
Hier staat een advertentie.

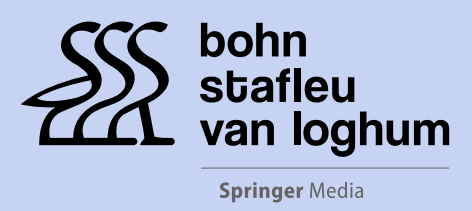

Houten 2019 
Hier staat een advertentie.

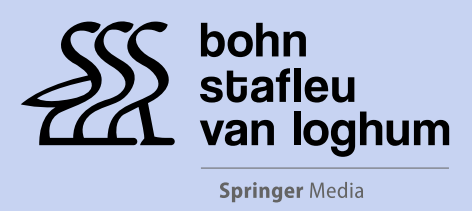

Houten 2019 
Tabel 1 Patiëntkenmerken

\begin{tabular}{|c|c|c|}
\hline & aantal & percentage $(\%)$ \\
\hline \multicolumn{3}{|l|}{ indicatie } \\
\hline mictieklachten & 60 & 74,1 \\
\hline recidiverende UWI's & 8 & 9,9 \\
\hline retentie & 7 & 8,6 \\
\hline overig $^{\mathrm{a}}$ & 6 & 7,4 \\
\hline \multicolumn{3}{|l|}{ oorzaak } \\
\hline katheterisatie & 13 & 16 \\
\hline trauma & 3 & 3,7 \\
\hline infectieus & 4 & 4,9 \\
\hline iatrogeen anderszins & 31 & 38,3 \\
\hline idiopathisch & 10 & 12,3 \\
\hline overig & 20 & 24,7 \\
\hline \multicolumn{3}{|l|}{ eerdere ingreep } \\
\hline geen & 17 & 21 \\
\hline Sachse & 44 & 54,3 \\
\hline dilatatie & 30 & 37 \\
\hline CIC & 22 & 27,2 \\
\hline EPA & 5 & 6,2 \\
\hline graftplastiek & 4 & 4,9 \\
\hline meerdere & 40 & 49,4 \\
\hline \multicolumn{3}{|l|}{ plastiek } \\
\hline EPA & 24 & 29,6 \\
\hline graftplastiek & 51 & 63 \\
\hline - dorsaal & 28 & 54,9 \\
\hline - ventraal & 26 & 51 \\
\hline - beide & 3 & 5,9 \\
\hline preputiumplastiek $^{\mathrm{b}}$ & 2 & 2,5 \\
\hline EPA + graftplastiek & 4 & 4,9 \\
\hline
\end{tabular}

$C I C$ Clean intermittent catheterization; EPA excisie en primaire anastomose; $U W I$ urineweginfectie

${ }^{\mathrm{a}} \mathrm{CIC}$ lukte niet meer of niet beschreven in status

${ }^{\mathrm{b}}$ Een full thickness graft en een gesteelde flap

gemiddelde leeftijd bedroeg 65 jaar (range 19-80). De gemiddelde follow-up was 28,1 maanden (range 3-72). Acht patiënten hadden diabetes mellitus en van zes patiënten was gedocumenteerd dat zij rookten. Vanwege de kleine aantallen werden deze potentiële risicofactoren buiten beschouwing gelaten. 60 patiënten werden behandeld wegens mictieklachten. 13 patiënten hadden een urethrastrictuur als gevolg van een traumatische katheterisatie en bij 31 patiënten was de oorzaak iatrogeen. Drie patiënten hadden een stomp trauma in de voorgeschiedenis. Bij tien patiënten was de oorzaak idiopathisch. 40 patiënten ondergingen eerder meerdere ingrepen wegens een urethrastrictuur. Dit betrof uit meerdere Sachses (tot 5 keer) of combinaties van Sachse, dilatatie, clean intermittent catheterization (CIC), eenmaal een Otis en bij sommige patiënten een plastiek. 51 patiënten kregen een graftplastiek, waarvan één full thickness graft (FTG) met preputium en één gesteelde preputiumflap. De overige grafts bestonden uit wangslijmvlies. 24 patiën- ten ondergingen een EPA en vier zowel een EPA als een graftplastiek in één sessie. Van de graftplastieken waren er 28 dorsaal, 26 ventraal en bij drie plastieken zowel dorsaal als ventraal (tab. 1).

De lengte van urethrastricturen varieerde van 0,14 $8,24 \mathrm{~cm}$, met een gemiddelde van $1,96 \mathrm{~cm}$. De strictuurlengte was bij 33 patiënten korter dan $1 \mathrm{~cm}$ en bij drie patiënten $5 \mathrm{~cm}$ of langer (fig. 1). Het merendeel van de stricturen was bulbair gelegen, 11 patiënten hadden zowel een bulbaire als een peniele strictuur.

De gemiddelde operatieduur was 157,71 minuten (range 58-281). Bij EPA's was dit 119,26 minuten (range 58-186) en bij graftplastieken 171,94 minuten (range 108-281).

De flow gemeten met uroflowmetrie was postoperatief significant verbeterd van een $\mathrm{Q}_{\max }$ van 9,69 preoperatief naar een gemiddelde $\mathrm{Q}_{\max }$ van 25 zes weken postoperatief $(p<0,01)$.

Bij 17 patiënten was sprake van een recidief, waarbij een re-interventie werd verricht: twee na een EPA, 14 na een graftplastiek en één na een EPA plus graftplastiek in één sessie. Dit maakt het overall succespercentage 79; het succespercentage van de EPA en graftplastiek beliep respectievelijk 91,7 en 72,5.

Bij korte en bulbaire stricturen ontstonden de meeste recidieven. Twee patiënten hadden een recidief nabij de sfincter. Bij twee patiënten $(11,8 \%)$ werden meerdere stricturen gezien. Eén patiënt had eerder radiotherapie van de prostaat ondergaan. Tien patiënten $(58,8 \%)$ hadden voorafgaand aan de plastiek meerdere strictuurbehandelingen ondergaan. Er waren evenveel dorsale als ventrale plastieken met een recidief. Zes patiënten met een recidief $(35,3 \%)$ hadden een urineweginfectie kort na de plastiek (zie tab. 2). Postoperatief bleef de transurethrale katheter gedurende drie weken in situ. Eén patiënt hield de transurethrale katheter twee weken langer wegens lekkage bij het controle urethrogram.

De duur tot recidief was gemiddeld 8,3 maanden (range 1-54) en de gemiddelde lengte was $0,49 \mathrm{~cm}$ (range $0,1-1,65 \mathrm{~cm}$, met twee uitschieters van 4,0 en $10,9 \mathrm{~cm})$. De patiënt met $4 \mathrm{~cm}$ recidief had een primaire strictuur van $4,5 \mathrm{~cm}$. De andere patiënt had meerdere kleine stricturen over een lengte van $10,9 \mathrm{~cm}$; hij onderging twee maanden na zijn urethraplastiek een percutane nefrolithotomie (PCNL) vanwege een symptomatische niersteen, met hierbij transurethrale instrumentatie voor het peroperatief plaatsen van een dubbel-J-katheter.

Vijftien patiënten kregen postoperatief een infectie, hiervan had één patiënt een wondinfectie en de overige patiënten een urineweginfectie. Vier patiënten kregen een urineweginfectie na een controle-urethrogram onder antibiotische profylaxe; bij drie patiënten was de bacterie niet gevoelig voor de standaard cotrimoxazolprofylaxe en bij 


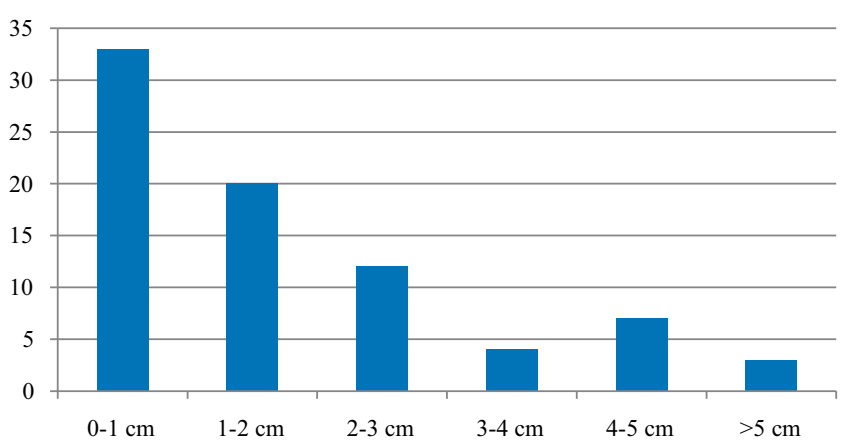

Figuur 1 Frequentie van de strictuurlengte

één patiënt was de bacterie resistent voor de aangepaste profylaxe die was gekozen op basis van een eerdere urinekweek. Negen patiënten hadden zowel een suprapubische katheter (SPC) als een transurethrale katheter postoperatief. Vier patiënten hadden een hematoom, waarvoor bij allen expectatief beleid gevoerd is (tab. 3). Informatie over langetermijncomplicaties werd met de telefonische en papieren enquête verkregen, waarbij 64 patiënten telefonisch zijn bereikt en 39 patiënten (48\% van het totaal aantal) de vragenlijst daadwerkelijk invulden.

21 patiënten hadden een erectiestoornis sinds de operatie, 25 patiënten ervoeren ook na de operatie nog plasklachten. 11 patiënten vonden hun penis korter na de operatie, van wie vijf patiënten postoperatief een kromstand van de penis opmerkten. Zes van de patiënten die verkorting bemerkten, hadden ook een erectiestoornis sinds de operatie. Eén patiënt heeft een jaar last gehad van hyperesthesie van het perineum en deze patiënt heeft sinds de operatie last van zijn heupen. Eén patiënt had een blijvend trekkend gevoel in de mond. Behoudens de mictieklachten en de hyperesthesie ervoeren de patiënten de langetermijncomplicaties niet als hinderlijk. De IIEF was bij 13 patiënten preoperatief ingevuld en bij negen patiënten postoperatief, maar geen van de patiënten had deze vragenlijst zowel pre- als postoperatief ingevuld.

Uit de vragenlijst en de telefonische enquête bleek dat $76,6 \%$ van de patiënten tevreden was na de operatie. De voornaamste redenen van ontevredenheid waren mictieklachten, zoals incontinentie of nadruppelen.

Het percentage recidieven lijkt af te nemen met de tijd, waardoor er een positieve trend lijkt te zijn in de leercurve van de operateur (fig. 2).

\section{Discussie}

In onze studie betrof het totale succes $79 \%$. Binnen de EPA's was het succespercentage 91,7 en binnen de graftplastieken 72,5. Van de patiënten met een recidief had $58,8 \%$ meerdere verrichtingen voor een urethrastrictuur on- dergaan voorafgaand aan de plastiek. Er werd postoperatief een significant betere $\mathrm{Q}_{\max }$ bij uroflowmetrie gemeten vergeleken met preoperatief. Een verminderde erectie na de plastiek werd door $22,8 \%$ van de patiënten vermeld, echter, dit is niet geobjectiveerd met behulp van verschil in IIEF pre- én postoperatief.

In onze studie was er een hoger succespercentage van de EPA dan van de graftplastiek. Santucci en Morey beschreven een succespercentage van de EPA van respectievelijk 95 en 93,8 [3, 4]. Het succespercentage bij Barbagli betrof in 200890 (EPA) en 81,8 (graftplastiek), met grafts van zowel preputium als wangslijmvlies [11].

In de literatuur wordt beschreven dat EPA's betere resultaten hebben bij korte bulbaire stricturen [1,5]. Dit is mogelijk een verklaring voor het succespercentage in onze studie, gezien het grote aantal korte bulbaire stricturen.

Er leek een trend in recidiefkans bij patiënten die in de voorgeschiedenis meerdere ingrepen voor een urethrastrictuur ondergingen. Barbagli et al. zagen een soortgelijke samenhang [11]. Breyer et al. bespraken eveneens meerdere ingrepen als risicofactor voor een recidief, en ook zij beschreven de lengte van de strictuur als een risicofactor voor recidief [12]. In onze studie ontstonden de meeste recidieven bij korte stricturen. Mogelijk omdat de meeste stricturen korter dan een $\mathrm{cm}$ waren en er een beperkt aantal patiënten was met een langere strictuur. In deze kliniek werden in het begin voornamelijk graftplastieken verricht. Gaandeweg ontstond er meer ervaring met de EPA en werd de indicatiestelling verruimd.

Er was geen verschil in recidiefpercentage bij plastieken met een ventrale of dorsale graft. Dit komt overeen met andere analyses, waarin ook geen verschil tussen ventrale en dorsale grafts werd gevonden $[6,13]$. Slechts één van de vijf patiënten met in de voorgeschiedenis radiotherapie van de prostaat had een recidief, waarbij een dorsale graftplastiek in de bulbaire urethra werd uitgevoerd. Uit de analyse die Hofer et al. uitvoerden naar urethrastricturen die door radiotherapie waren geïnduceerd, kwam radiotherapie ook niet naar voren als risicofactor voor het ontstaan van een recidief [14]. In onze studie kan uit het kleine aantal patiënten hierover geen conclusie worden getrokken.

Een niet geslaagde plastiek werd gedefinieerd als een recidief strictuur waarvoor enige vorm van interventie volgde. In de literatuur is nog geen consensus over de enige juiste definitie. In de systematische review van Meeks et al. werd onderscheid gemaakt tussen het soort ingreep dat volgde op een plastiek: dilatatie of een chirurgische ingreep. Ook includeerden zij studies waaruit bleek dat de noodzaak tot eenmalige dilatatie na een plastiek niet werd gezien als recidief [15]. Morey et al. beschreven in hun review meerdere variaties van de definitie, waaronder aanwezigheid van symptomen die passen bij een strictuur, de noodzaak tot enige interventie na een plastiek en de aanwezigheid van 
Tabel 2 Factoren bij recidieven

\begin{tabular}{|c|c|c|}
\hline & aantal & percentage $(\%)$ \\
\hline \multicolumn{3}{|l|}{$\overline{\text { plastiek }}$} \\
\hline EPA & 2 & 11,8 \\
\hline graftplastiek & 14 & 82,4 \\
\hline a. dorsaal & 7 & 41,2 \\
\hline b. ventraal & 7 & 41,2 \\
\hline $\mathrm{EPA}+$ graftplastiek & 1 & 5,9 \\
\hline \multicolumn{3}{|l|}{ eerdere ingreep } \\
\hline dilatatie & 2 & 11,8 \\
\hline CIC & 1 & 5,9 \\
\hline meerdere & 10 & 58,8 \\
\hline radiotherapie prostaat & 1 & 5,9 \\
\hline \multicolumn{3}{|l|}{ lengte preoperatief } \\
\hline$<1 \mathrm{~cm}$ & 6 & 35,3 \\
\hline $1-2 \mathrm{~cm}$ & 4 & 23,5 \\
\hline $2-3 \mathrm{~cm}$ & 5 & 29,4 \\
\hline $4-5 \mathrm{~cm}$ & 2 & 11,8 \\
\hline \multicolumn{3}{|l|}{ locatie } \\
\hline bulbair & 13 & 76,5 \\
\hline peniel & 2 & 11,8 \\
\hline beide & 2 & 11,8 \\
\hline meerdere stricturen & 2 & 11,8 \\
\hline \multicolumn{3}{|l|}{ complicaties } \\
\hline urineweginfecties & 6 & 35,3 \\
\hline $\begin{array}{l}\text { lekkage bij controle } \\
\text { urethrogram }\end{array}$ & 1 & 5,9 \\
\hline
\end{tabular}

$C I C$ clean intermittent catheterization; EPA excisie en primaire anastomose

Tabel 3 Complicaties

\begin{tabular}{lcc}
\hline & aantal & percentage (\%) \\
\hline wondinfectie & 1 & 1,2 \\
urineweginfectie & 14 & 17,3 \\
hematoom & 4 & 4,9 \\
klachten mond & 1 & 1,2 \\
verminderde erecties & 21 & 25,9 \\
kromstand penis & 5 & 6,2 \\
verkorting penis & 11 & 13,6 \\
mictieklachten & 25 & 30,1 \\
hypesthesie perineum & 1 & 1,2 \\
pijn heupen & 1 & 1,2 \\
\hline
\end{tabular}

een strictuur die was gediagnosticeerd bij aanvullend onderzoek, ongeacht de noodzaak tot interventie. Ook waren er studies waarbij een vragenlijst hierin bepalend was [4].

De lengte van de strictuur werd in ons onderzoek gemeten aan de hand van het preoperatieve X-RUG. De lengte werd ook peroperatief gemeten. In sommige gevallen kwam die lengte niet overeen met de preoperatief gemeten lengte. Angelmeier et al. beschrijven een sensitiviteit van de X-RUG van 72-97\% vergeleken met cystoscopie en peroperatieve meting [7]. Doordat data in het statusonderzoek ontbreken, hebben wij er in ons onderzoek voor gekozen de lengte die op de X-RUG werd gemeten aan te houden als lengte voor de urethrastrictuur. Overigens werd aan de hand van de peroperatieve bevindingen de te gebruiken operatietechniek gekozen.

Wij hebben de tevredenheid van patiënten gescoord aan de hand van een telefonische enquête en een vragenlijst. Op deze manier hebben wij 64 patiënten (79\%) bereikt met de telefonische enquête en 39 patiënten ( $48 \%$ van alle patiënten) vulden de vragenlijst in. Daaruit bleek een tevredenheid van $76,6 \%$. Ontevredenheid kwam voornamelijk door postoperatieve mictieklachten. Het overgrote deel van de patiënten gaf aan tevreden te zijn met de zorg en de procedure. Barbagli et al. gebruikten een vragenlijst waarbij hij ook de tevredenheid van zijn patiënten bepaalde: twee van zijn patiënten waren ontevreden wegens postoperatieve pijn en een koude glans [16]. Guralnick en Webster gebruikten alleen een telefonische enquête ter evaluatie van de tevredenheid. In zijn onderzoek waren alle patiënten tevreden met de uitkomst van de operatie, ondanks recidieven [8]. Noch onze vragenlijst, noch die van de hiervoor genoemde onderzoekers waren gevalideerd.

In onze studie had $22,8 \%$ van de patiënten postoperatief een verminderde erectiele functie. Bij een aantal patiënten was dit van voorbijgaande aard. Er is geen IIEF-scorelijst voor én na de operatie bijgehouden, waardoor een objectief oordeel niet mogelijk is. Het soort ingreep kan een rol spelen in het ontstaan van verminderde erecties. Dugi III beschrijft een verhoogde kans op erectiele disfunctie bij EPA's door het doornemen van de urethra, waarbij mogelijk vasculaire en zenuwstructuren zijn geraakt [13]. Met een gemiddelde leeftijd van 56 jaar is onze patiëntenpopulatie ouder dan die in de meeste andere analyses. De afname in erecties deed zich voor in de oudere helft van onze patiëntenpopulatie. Morey et al. beschrijven een slechtere uitkomst voor seksuele functie bij ouderen en bij langere stricturen [4]. Wij vonden geen aanwijzing voor samenhang tussen de lengte van de strictuur en het ontstaan van erectiele disfunctie. Wij adviseren om pre- en postoperatief een IIEF-scorelijst bij te houden om tot een objectieve beoordeling te kunnen komen.

Barbagli benoemt dat penisverkorting en kromstand kan optreden na een EPA [6]. In onze studie bemerkten 11 patiënten verkorting en vijf van hen ook kromstand van de penis; het merendeel van deze patiënten onderging echter een graftplastiek. Een verklaring kan zijn dat eenzijdige samentrekking van het nieuwe eenzijdige litteken ontstaat. De kromstand en verkorting zijn niet objectief gemeten, maar werden door de patiënt anamnestisch aangegeven. Hierdoor kan de daadwerkelijke mate van verkorting en kromstand niet worden vastgesteld. 


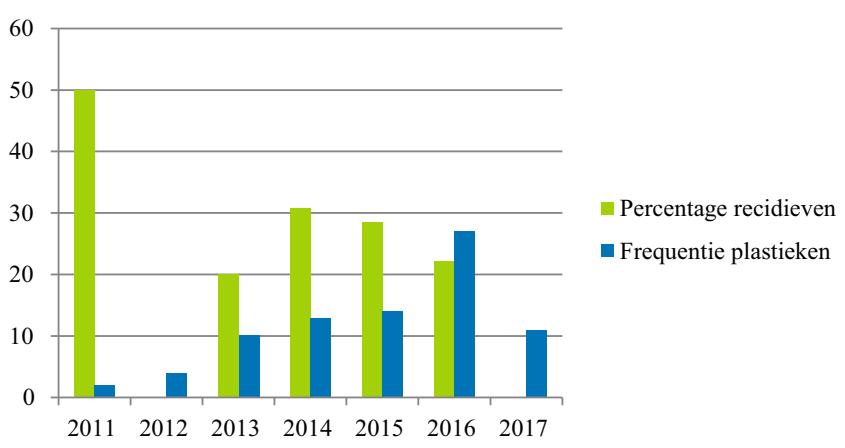

Figuur 2 Percentage recidieven per jaar

Slechts één patiënt heeft spontaan aangegeven dat hij een blijvend trekkend gevoel had in de mond na de graftplastiek. Hoewel dit niet expliciet is nagevraagd, hebben wij de indruk dat dit probleem niet vaak voorkomt bij onze patiëntenpopulatie.

Een aantal patiënten had postoperatief mictieklachten, onder andere incontinentie, nadruppelen en een slappere straal. Een deel van deze klachten kan veroorzaakt zijn door de vaak wijdere urethra na een graftplastiek, met stase van urine. Tevens kan een component van benigne prostaathyperplasie (BPH) meespelen. Santucci et al. suggereren patiënten met mictieklachten bij BPH preoperatief medicamenteus te behandelen [17].

Er was sprake van een urineweginfectie bij $18 \%$ van de patiënten. Dit was voornamelijk bij patiënten met postoperatief zowel een transurethrale katheter als een SPC. Niet een van de patiënten had preoperatief recidiverende urineweginfecties. Daarnaast werd preoperatief bij elke patiënt een urinekweek afgenomen ter bepaling van profylaxe. Bij de vier patiënten die een infectie kregen na het controleurethrogram bleek de bacterie resistent voor de gebruikte antibioticumprofylaxe. Er kan worden overwogen extra adviezen inzake de hygiëne te geven aan patiënten met twee katheters. Gezien het kleine aantal patiënten met infectie na urethrogram lijkt het kweken van urine voorafgaand aan dit onderzoek niet van toevoegende waarde ter preventie van infecties.

Met postoperatief een significant betere uitkomst bij uroflowmetrie lijkt er objectief bewijs te zijn voor verbetering van de mictie na de plastiek. Ook sterkt dit ons in de aanbeveling van uroflowmetrie als een methode voor monitoring tijdens follow-up, mits uroflowmetrie preoperatief wordt verricht [7].

De operaties werden door één operateur verricht. In de loop der jaren werden percentueel minder recidieven gezien. Dit kan deels verklaard worden door een leercurve. Echter, de kanttekening hierbij is dat er ook procentueel meer EPA's verricht zijn in deze periode, wat de recidiefkans verlaagt, ondanks dat er steeds complexere stricturen zijn behandeld.
Onze studie kende ook enkele beperkingen. Zo ging het om een retrospectieve studie. Bij statusonderzoek kampten wij met ontbrekende data. De patiëntengroep was te klein voor uitgebreide statistische analyse. Bij de telefonische en schriftelijke enquête kan er sprake zijn geweest van herinneringsbias bij de patiënt. Bij afwezigheid van een gestandaardiseerde vragenlijst en geen IIEF, noch preoperatief, noch postoperatief, was objectivering van de tevredenheid en van de langetermijncomplicaties niet mogelijk.

\section{Conclusie}

Het overall succespercentage van de urethraplastiek in het Franciscus Gasthuis is 79. Bij de EPA is dit 91,7 en bij de graftplastiek 72,5. Dat komt overeen met de in de literatuur beschreven resultaten. Meerdere strictuuringrepen in de voorgeschiedenis zijn mogelijk een risicofactor voor het ontstaan van een recidief na urethraplastiek. De erectiele disfunctie, al dan niet van voorbijgaande aard, is mogelijk een belangrijke complicatie, waarover patiënten preoperatief goed dienen te worden voorgelicht. Het afnemen van de IIEF-vragenlijst voor en na de plastiek wordt aanbevolen.

Open Access This article is distributed under the terms of the Creative Commons Attribution 4.0 International License (http:// creativecommons.org/licenses/by/4.0/), which permits unrestricted use, distribution, and reproduction in any medium, provided you give appropriate credit to the original author(s) and the source, provide a link to the Creative Commons license, and indicate if changes were made.

\section{Literatuur}

1. Mundy A, Andrich A. Urethral strictures. BJU Int. 2010;107:6-26.

2. Wong S, Aboumarzouk O, Narahari R, O'Riordan A, Pickard R. Simple urethral dilatation, endoscopic urethrotomy and urethroplasty for urethral stircture disease in adult men (review). Cochrane Database Syst Rev. 2012; https://doi.org/10.1002/ 14651858.cd006934.pub3.

3. Nederlandse Vereniging voor Urologie. Richtlijn Urethrastricturen. 2017.

4. Morey AF, Watkin N, Shenfeld O, Eltahawy E, Giudice C. SIU/ ICUD consultation on urethral strictures: anterior urethra - primary anastomosis. Urology. 2014;83:S23-S6.

5. Santucci R, Mario L, McAninch J. Anastomotic urethroplasty for bulbar urethral stricture: analysis of 168 patients. J Urol. 2002;167:1715-9.

6. Barbagli G, Sansalone S, Djinovic R, Romano G, Lazzeri M. Current controversies in reconstructive surgery of the anterior urethra: a clinical overview. Int Braz J Urol. 2012;38(3):307-16.

7. Angermeier K, Rourke K, Dubey D, Forsyth R, Gonzalez C. SIU/ ICUD consultation on urethral strictures: evaluation and follow-up. Urology. 2014;83:S9-S17.

8. Guralnick M, Webster G. The augmented anastomotic urethroplasty: indications and outcome in 29 patients. J Urol. 2001;165: 1496-501.

9. Peeling W. Diagnostic assessment of benign prostatic hyperplasia. Prostate. 1989;2:51-68. 
Hier staat een advertentie.

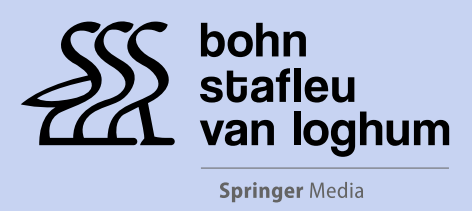

Houten 2019 
Hier staat een advertentie.

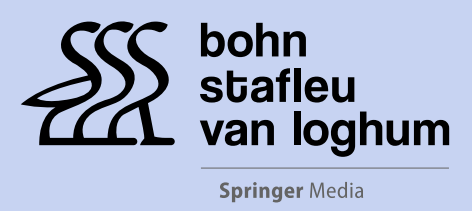

Houten 2019 
10. VUmc afdeling urologie. Concept PROM vragenlijst urethrastrictuur. 2017.

11. Barbagli G, Guazzoni G, Lazzeri M. One-stage bulbar urethroplasty: retrospective analysis of the results in 375 patients. Eur Urol. 2008;53:828-33.

12. Breyer B, McAninch $\mathrm{J}$, Whitson $\mathrm{J}$, et al. Multivariate analysis for risk factors for long-term urethroplasty outcome. J Urol. 2010;183:613-7.

13. Dugi D III, Simhan J, Morey A. Urethroplasty for stricture disease: contemporary techniques and outcomes. Urology. 2016;89:12-8.

14. Hofer M, Zhao L, Morey A, et al. Outcomes after urethroplasty for radiotherapy induced bulbomembranous urethral stricture disease. J Urol. 2014;191:1307-12.

15. Meeks J, Erickson B, Granieri M, Gonzalez C. Stricture recurrence after urethroplasty: a systematic review. J Urol. 2009;182:1266-70.
16. Barbagli G, De Angelis M, Romano G, Lazzeri M. Long-term follow up of bulbar end-to-end anastomosis: a retrospective analysis of 153 patients in a single center experience. J Urol. 2007;178:2470-2.

17. Santucci R, McAninch J, Mario L, et al. Urethroplasty in patients older than 65 years: indication, results, outcomes and suggested treatment modifications. J Urol. 2004;172:201-3.

drs. Pauline C. Wesselman van Helmond anios urologie

drs. Ronald I. Nooter uroloog

drs. Anna V. van Lingen uroloog 